

\title{
TERMINAL RODOVIÁRIO DE CAJAZEIRAS: acessível para todos?
}

\section{CAJAZEIRAS BUS TERMINAL: accessible for everyone?}

\author{
MAÍRA TALITA VIEIRA DA SILVA \\ Graduanda em Arquitetura e Urbanismo, Faculdade Santa Maria/PB \\ mairatalita17@hotmail.com \\ MARIA JOYCE LIMA DE SOUSA \\ Graduanda em Arquitetura e Urbanismo, Faculdade Santa Maria/PB \\ joycelimaa03@hotmail.com \\ MARJORIE MARIA ABREU GOMES DE FARIAS \\ Professora e orientadora da Faculdade Santa Maria/PB \\ marjorieabreu.arq@gmail.com
}

\section{RESUMO}

Essa pesquisa possui como objetivo avaliar as condições de acessibilidade do Terminal Rodoviário Clóvis Rolim, em Cajazeiras na Paraíba, fundamentada a informações da NBR 9050/2015. Devido à importância social e cultural do Terminal Rodoviário para a cidade, é salutar a consideração a sua infraestrutura, que, nos dias atuais, não se enquadra devidamente nos requisitos de acessibilidade urbana. A metodologia foi dividida em pesquisa bibliográfica, visita in loco, análise com base em checklist de acessibilidade e registro fotográfico comprobatório. Como resultado percebeu-se quanto à acessibilidade, a presença de diversas barreiras físicas que dificultam o acesso ao terminal, como também, ausência de sinalização de alerta para pessoas com deficiência visual, simbologia de orientações para deficientes auditivos e informações verticais e horizontais informativas como um todo. Por fim, o entendimento é de que no espaço há grau considerado de inacessibilidade que dificulta o acesso para os usuários e não leva em conta a lei vigente de acessibilidade.

PALAVRAS-CHAVE: Acessibilidade, terminal rodoviário, espaço público.

\section{ABSTRACT}

This research aims to evaluate the accessibility conditions of the Clóvis Rolim Bus Terminal, in Cajazeiras Paraíba, based on information from NBR 9050/2015. Due to the social and cultural importance of the Bus Terminal for the city, it is salutary to consider its infrastructure, which, nowadays, does not fit properly in the requirements of urban accessibility. The methodology was divided into bibliographic research, on-site visit, accessibility checklist-based analysis and supporting photographic record. As a result, the presence of several physical barriers that hinder access to the terminal was noticed, as well as the absence of warning signs for visually impaired people, symbology 


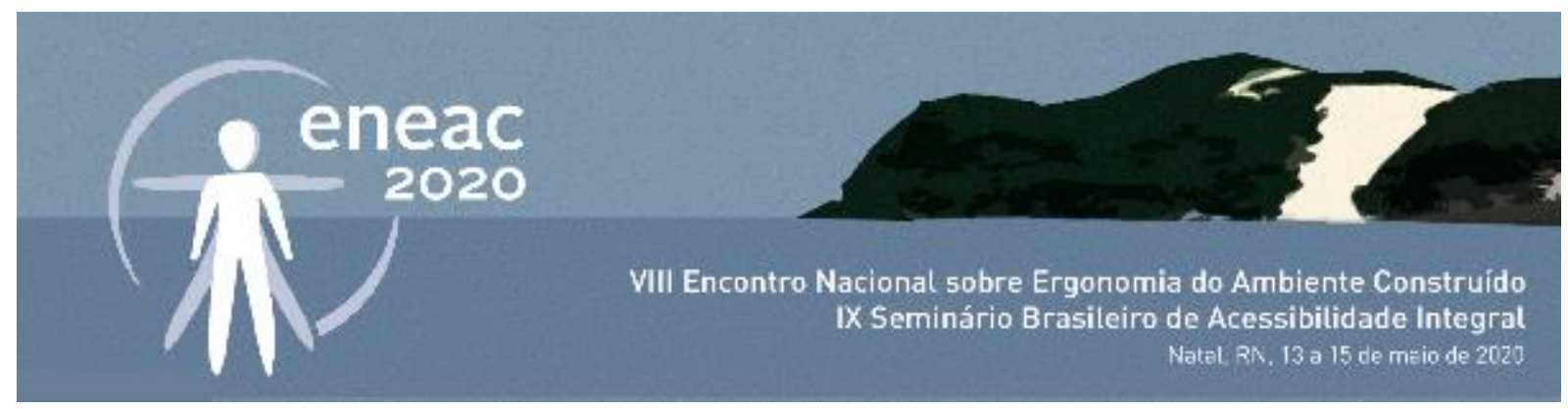

of guidelines for the hearing impaired and informative vertical and horizontal information as a all. Finally, the understanding is that in space there is a degree of inaccessibility that makes access difficult for users and does not take into account the current accessibility law.

KEYWORDS: Accessibility, bus Terminal, public place.

\section{INTRODUÇÃO}

Por sua estratégica localização, cortada por 03 rodovias, sendo 01 federal, a Rodovia Governador Antônio Mariz (BR-230) e 02 estaduais (PB-393 e PB-400), e por abrigar diversas instituições de ensino superior, a cidade de Cajazeiras/PB é ponto de embarque e desembarque de centenas de pessoas todos os dias. Um dos meios de locomoção mais utilizados para transporte de bagagens e passageiros é viabilizado através do Terminal Rodoviário Clóvis Rolim, construído no final do século $\mathrm{XX}$.

Segundo dados do Governo da Paraíba (FERNANDES, Gabriela. 2019), mais de 10 mil passageiros circulam mensalmente neste espaço. Um número que, se comparado à população total de Cajazeiras, levantada pela estimativa do IBGE em 2010 , que seria de $\sim 62.000$, resultaria em $16 \%$ dos habitantes (IBGE, 2010).

Devido a importância social e cultural do Terminal Rodoviário para a cidade, é salutar a consideração a sua infraestrutura, que, nos dias atuais, não se enquadra devidamente nos requisitos de acessibilidade urbana.Para tanto, o presente estudo se desenvolve com o intuito de analisar este espaço e apontar os problemas e questões acerca da sua acessibilidade.

De acordo com a NBR 9050 (ABNT, 2015, p.16), "acessibilidade é a possibilidade e condição de alcance, percepção e entendimento para utilização, com segurança e autonomia, de espaços, mobiliários, equipamentos urbanos e edificações". Em outras palavras, acessibilidade é a maneira de possibilitar a aproximação entre indivíduos em locais de diferentes âmbitos, sendo através dela que ocorre a inclusão e interrelação de pessoas.

A cidadania do indivíduo é uma combinação entre desenvolvimento pleno e sua capacidade de locomover-se, mesmo diante de limitações. Algumas pessoas podem apresentar diferenças em sua capacidade de locomoção e, por este motivo, podem sentir-se excluídas pela sociedade.

De acordo com dados do IBGE (2010), Cajazeiras possui entre 1500 a 2000 pessoas com algum tipo de dificuldade de percepção ou locomoção, sejam elas de maneira temporária ou permanente. Por esta razão, este número não deve ser apenas uma estatística, o que implica na importância real deste estudo, de valor significativo para sociedade.

\section{ACESSIBILIDADE E LEGISLAÇÃO}

Apesar do termo acessibilidade ser bastante conhecido, algumas pessoas ainda a relacionam apenas à rampas ou mesmo as pessoas com deficiência, contudo, trata-se de um conceito muito mais amplo, já que se trata de dá acesso e utilizar espaços com segurança e autonomia à todos independente de sexo, idade, gênero, ou mesmo de alguma limitação física ou psicológica. 


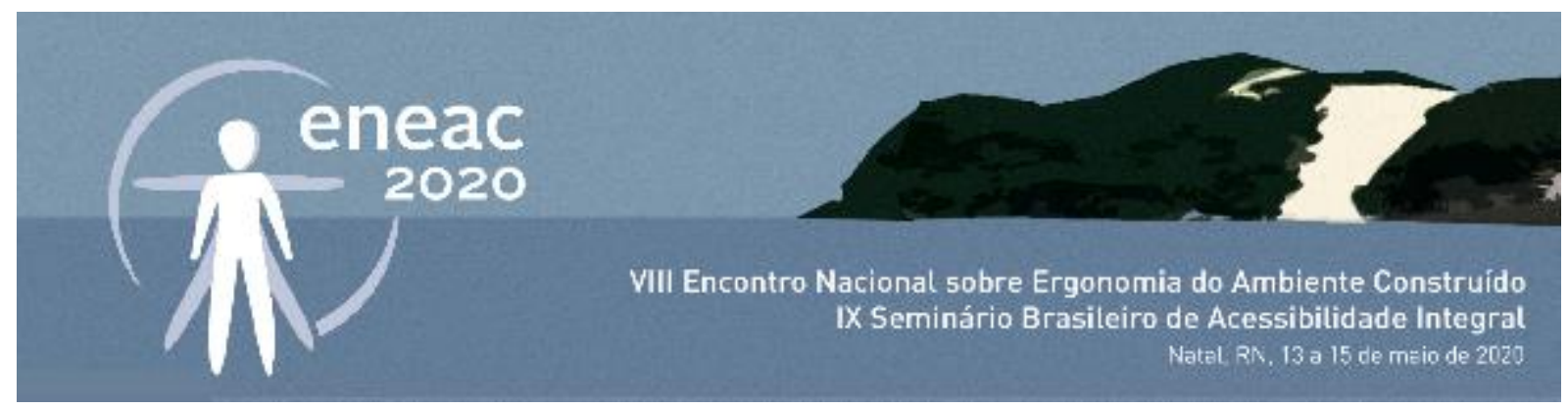

Sassaki (2004) acredita que a acessibilidade não mais se restringe ao espaço físico, uma vez que é possível encontrar várias outras barreiras que ultrapassam a dimensão arquitetônica. Para Kinsky (2004), "o termo acessibilidade está ligado à superação de barreiras", previstas no artigo 5o da Constituição Federal (1988) no qual todos são iguais perante a lei sem distinção de qualquer natureza. Lamônica et al. (2008) reafirmam que a acessibilidade é assegurada por lei para permitir aos portadores de deficiência no exercício da cidadania, tenham a possibilidade de desfrutar da vivência no meio social e finaliza dizendo que "[...] barreiras arquitetônicas interferem na vida destes podendo deixá-los a parte da convivência e vida social.".

Nesse contexto pode-se ressaltar também a importância da acessibilidade espacial que significa bem mais do que poder atingir um lugar desejado, é também necessário que o local permita ao usuário compreender sua função, sua organização e relações espaciais, assim como participar das atividades que ali ocorrem (BINS ELY et al., 2012, p.28) .

Diante do exposto, a acessibilidade vai muito além de normas, ela engloba condições de segurança e conforto, por meio de serviços, produtos, dispositivos e sistemas de informação, atribuído aos diversos grupos de usuários, atendendo a todos os espaços públicos, privados e espaços edificados ou não.

No Brasil, existem leis federais e municipais, decretos, resoluções e normas que estabelecem suporte legal ao direito da pessoa com deficiência. A exemplo da Lei Federal 10.098 (BRASIL, 2000) que estabelece as normas gerais e os critérios básicos para promover acessibilidade à todas as pessoas com deficiência ou com mobilidade reduzida. Tomando como base esta lei, os estados elaboram legislação específica para o atendimento das normas estabelecidas.

Assim como também tem o Decreto no 5.296 (BRASIL, 2006) que afirma que Acessibilidade está diretamente ligada a fornecer condições para utilização, com segurança e autonomia, total ou assistida, dos espaços, mobiliários e equipamentos urbanos, das edificações, dos serviços de transporte e dos dispositivos, sistemas e meios de comunicação e informação, por pessoa com deficiência ou com mobilidade reduzida.

Este trabalho aborda a acessibilidade em uma edificação pública, mais precisamente um terminal rodoviário, que é um local onde existe grande fluxo de pessoas diariamente, logo se faz mais do que necessário que a acessibilidade seja efetiva e contemple a todos.

Ao se falar de edificações rodoviárias tem-se a NBR 15320 (2005) que trata da acessibilidade a pessoas com deficiência no transporte rodoviário, levando em conta parâmetros para que os terminais rodoviários possibilitem a integração, com acessibilidade, a outros meios e modos de transportes.

As definições contidas na norma são importantes para que sejam observadas e respeitadas nas construções novas ou as que necessitam de reformas, e, há regras específicas para tal, facilitando o acesso a diversos ambientes e promovendo a independência e desenvolvimento das pessoas com deficiência (MAZZONI et al. 2001; MORAES, 2007).

Um dos elementos relevantes em um terminal rodoviário para garantir o acesso, possibilitando passagem ou permanência dos usuários é a sinalização. A sinalização deve ser garantida de diversas formas, sejam horizontais, verticais, para deficientes visuais, auditivos, entre outros. 


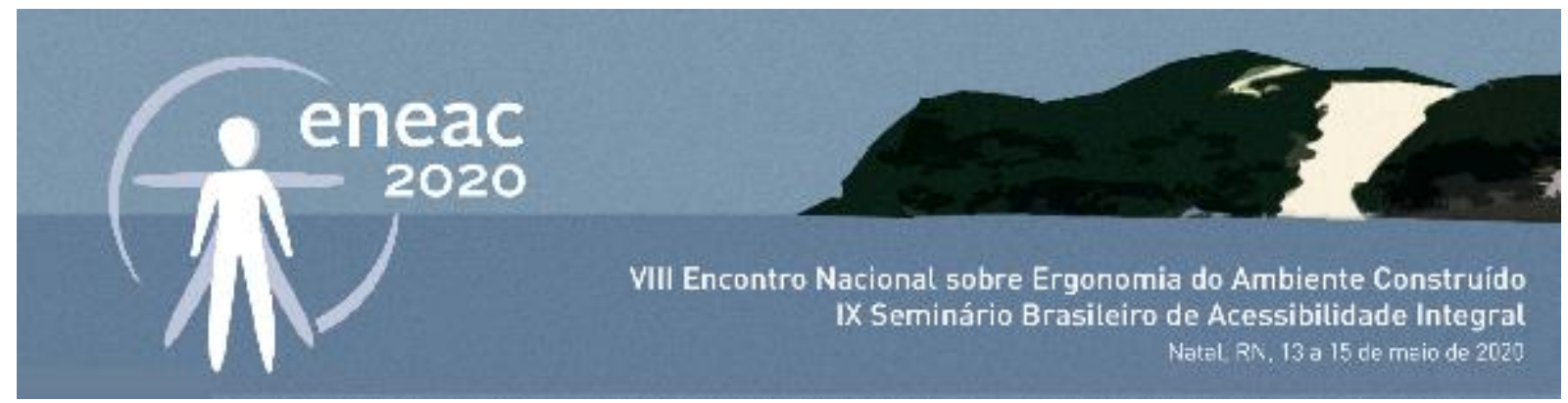

Para indicar que o local, mobiliário e equipamentos urbanos estão dentro dos parâmetros de acessibilidade a pessoas com deficiência ou mobilidade reduzida, a NBR 9050 (ABNT, 2015) determina que uma simbologia específica de indicação, esteja afixada em pontos estratégicos como entradas, estacionamentos, sanitários, áreas de embarque e desembarque, entre outros. A placa de sinalização deverá estar locada em um nível de ampla visualização, podendo esta, ser representada em 3 modelos de diferentes cores (figura 01), como mostrados abaixo:

Figura 01- Representação de simbologia de acessibilidade.
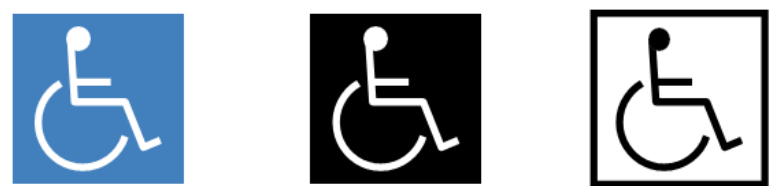

Fonte: ABNT NBR 9050 (2015).

Cada tipo de necessidade especial e atendimento preferencial exige um símbolo adequado definido em norma e que não permite nenhum tipo de mudança, devendo ser representado da seguinte forma (figura 02):

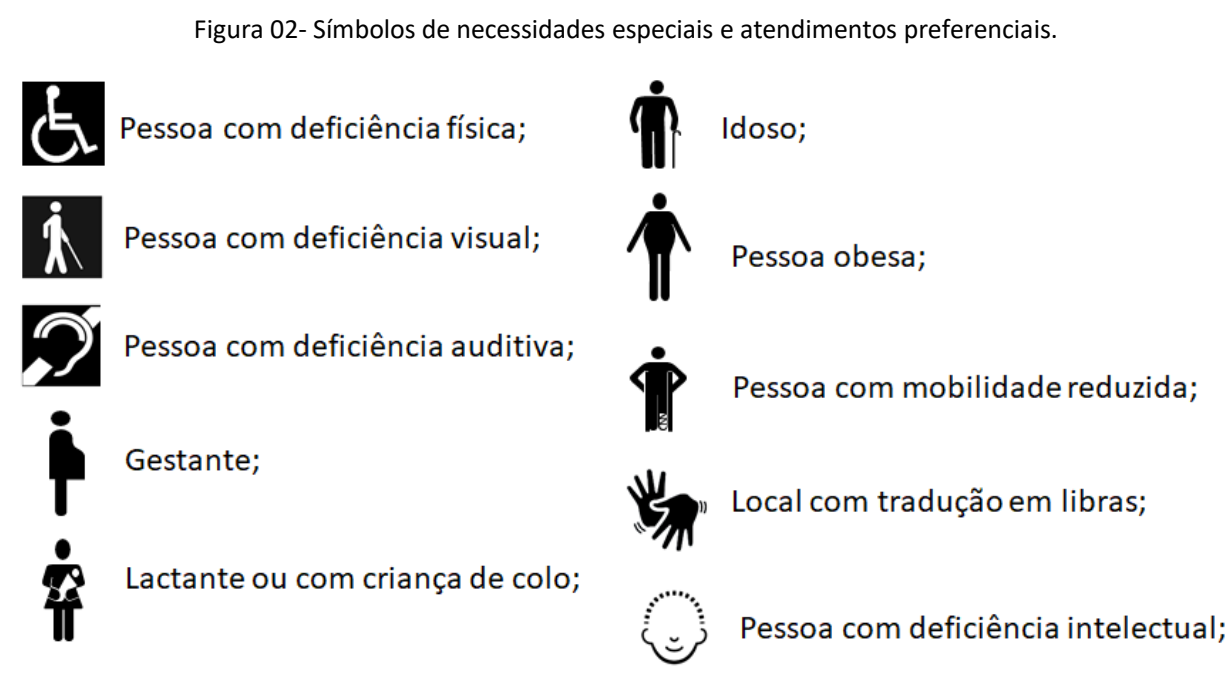

Fonte: ABNT NBR 9050 (2015).

Sendo assim, é importante que haja a propagação de conhecimento a respeito dos termos e variáveis que englobam acessibilidade e ambiente acessível. Para que, por falta de entendimento, usuários deixem de usufruir de espaços para eles pensados. 


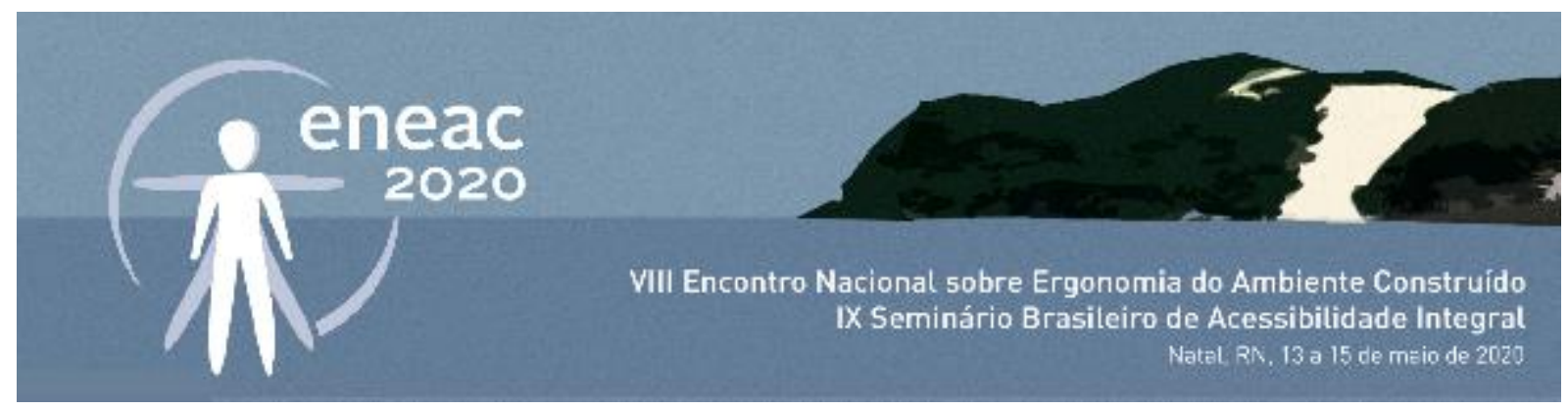

\section{METODOLOGIA}

Para o desenvolvimento desta pesquisa, inicialmente, foi realizado um levantamento bibliográfico, o qual baseou-se em princípios e conceitos de acessibilidade, que possibilitam a circulação de pessoas com deficiências (motoras, auditivas e perceptivas) ou mobilidade reduzida de longa ou curta permanência.

Posteriormente, visita in loco com análise de acessibilidade, através de checklist (lista de verificação) adaptado do Manual Prático de Acessibilidade (2018). Esse checklist foi escolhido por enquadrar-se nos quesitos do Terminal analisado. Ainda nessa mesma etapa, registros fotográficos foram realizados para comprobação dos dados obtidos com a análise visual e perceptiva, derivada do checklist.

\section{RESULTADOS}

O estudo foi realizado no Terminal Rodoviário Clóvis Rolim, que teve implantação em 1990, está localizado em uma área comercial delimitada pela Rua Dr. José Moreira de Figueiredo e Avenida Comandante Vital Rolim, no bairro do Centro na cidade de Cajazeiras - Paraíba (figura 03). Desde então, teve uso contínuo e de suma importância para a população. Sua prestabilidade se dá pela beneficiada localização em ponto estratégico e cercada por divisas de Estados. O que possibilita uma diversa gama de serviços como por exemplo o transporte de pessoas, bagagens, assim como translado intermunicipais e interestaduais.

Figura 03- Implantação no lote. Indicação do Terminal e seus estacionamentos.

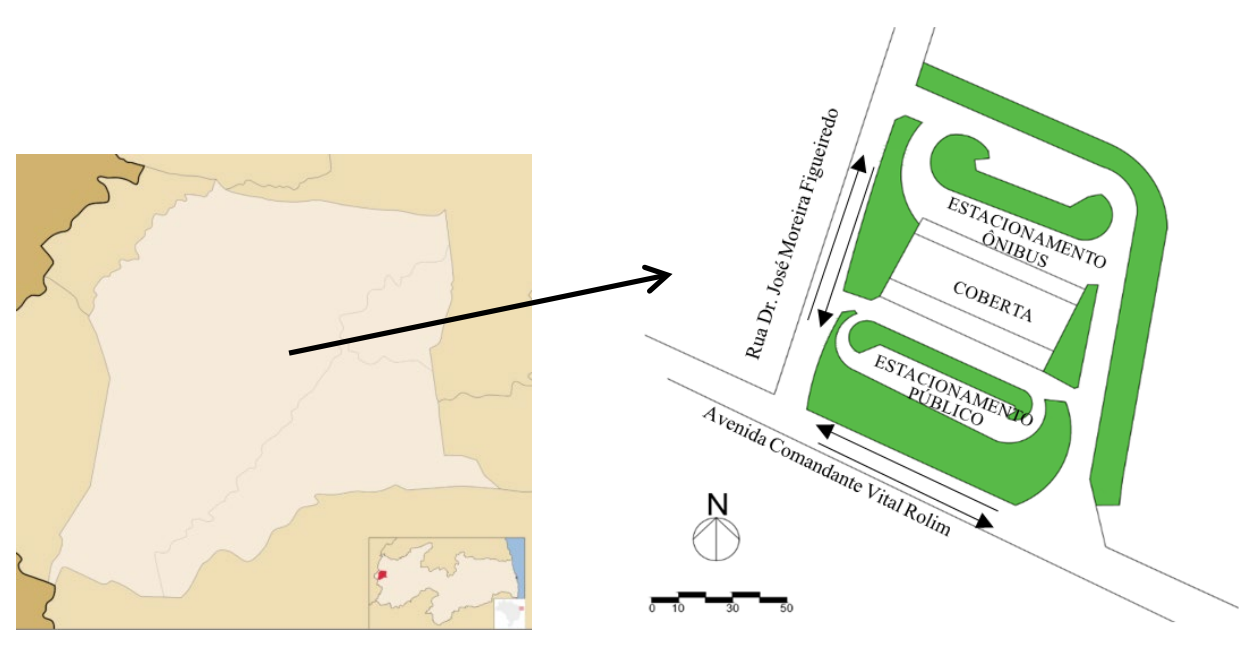

Fonte: Acervo próprio (2019).

Em relação ao acesso, esse terminal possui apenas dois: um para veículos de passeio e um para pedestres (figura 04), que por sua vez, se dá através de uma via veicular que não possui presença de rampas acessíveis ou área planificada que torne possível o caminho a todos. Há existência de meio 


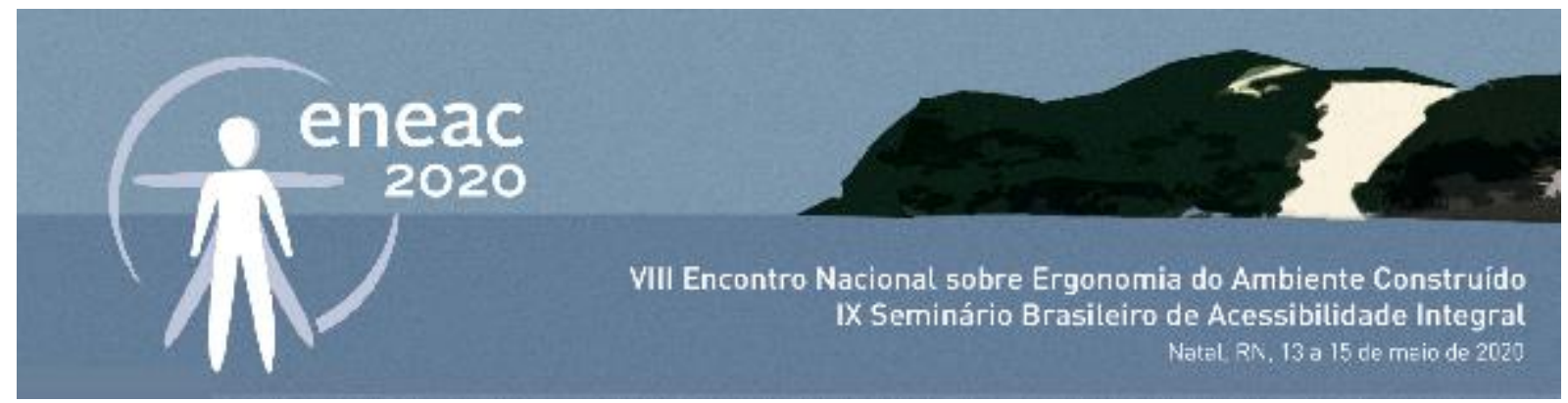

fios inadequados e valas de esgotamento (figura 05) que também acabam por se tornar mais um obstáculo.

Figura 04- Acesso de pedestres sem rampas, sinalização ou entradas prioritárias.



Fonte: Acervo próprio (2019).

Figura 05- Meio fios com ausência de rampa de acesso e vala de esgotamento aberta.

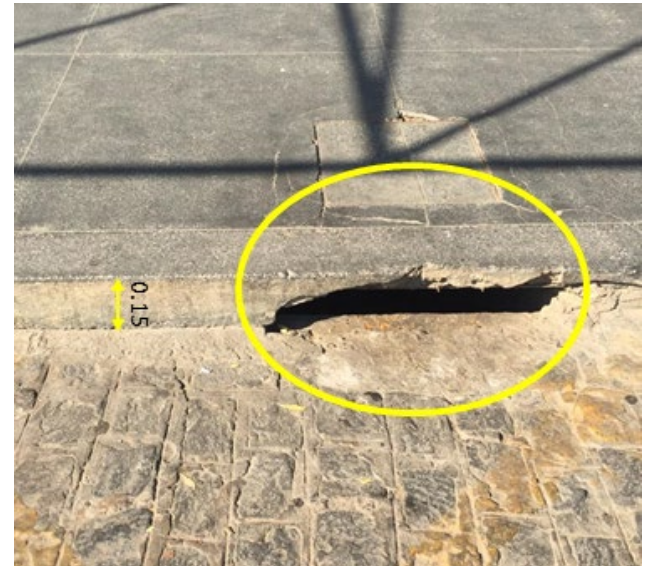

Fonte: Acervo próprio (2019).

Com relação às áreas de saída, que se encontram entre a passagem de pedestres para acesso ao terminal e do terminal para acesso ao estacionamento, os desníveis se configuram como responsáveis por prejuízos ou empecilho de locomoção dos usuários (figura 06).

O trajeto do estacionamento até o Terminal é configurado por uma série de barreiras, que acabam por dificultar a mobilidade de indivíduos que possuam qualquer tipo de limitação, temporária ou permanente. Iniciando-se com a passagem por uma calçada de piso irregular cimentício e com espaços esburacados (figura 06). 


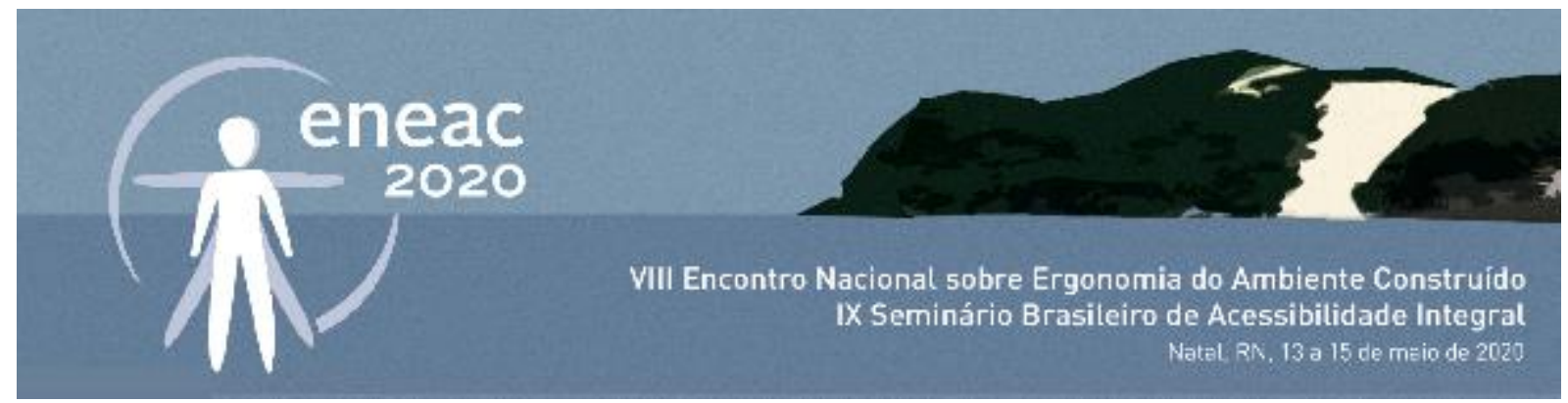

Figura 06- Adversidades encontradas no trajeto do estacionamento para o Terminal.
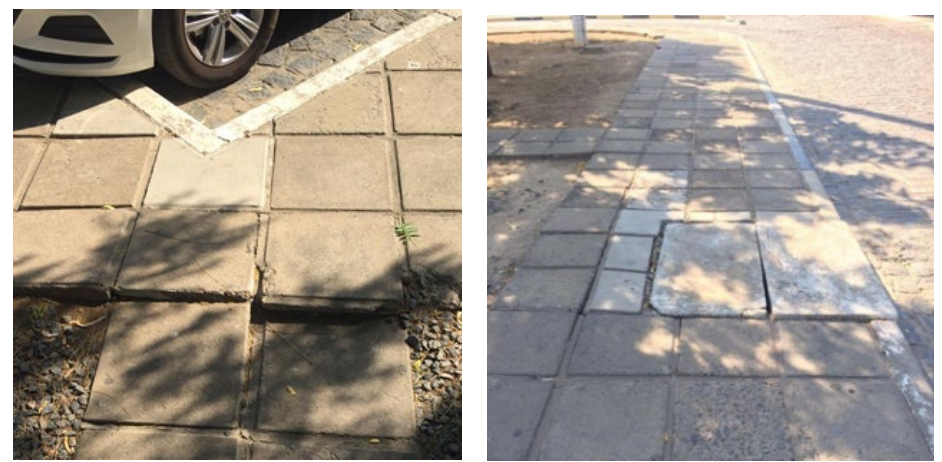

Fonte: Acervo próprio (2019).

As calçadas que rodeiam toda a edificação, possuem largura superior à 1,20m, mínima imposta pela NBR 9050/15, mas em contrapartida não possuem piso tátil de identificação ou sinalizações verticais e horizontais.

A falta de manutenção e o mau uso resultaram em adversidades de percurso (figura 07) que podem minimizar ou impedir a circulação de pedestres. Tratando-se ainda de pisos, os utilizados em geral, não dispõem de uso de material antiderrapante. Em alguns pontos casuais das calçadas, podem ser encontradas lixeiras e vegetações a baixo de 2,10m (mínimo exigido pela NBR 9050), o que prejudica tanto no passeio como na iluminação dessas áreas.

O percurso para uma via interna de acesso veicular, possui grau considerado de trepidação e desnivelamento do piso, que visivelmente não foi pensado com diferenciação para pedestres e veículos, meio fios com alturas inadequadas (Figura 07) e mais uma vez, ausência de rampas, como também, há falta de sinalização de localização (composta por símbolos), de advertência (podendo ser sonora e visual) e de instrução (composta por elementos em Braille, sejam pisos ou mapas).

Figura 07- Altura considerável do meio fio.

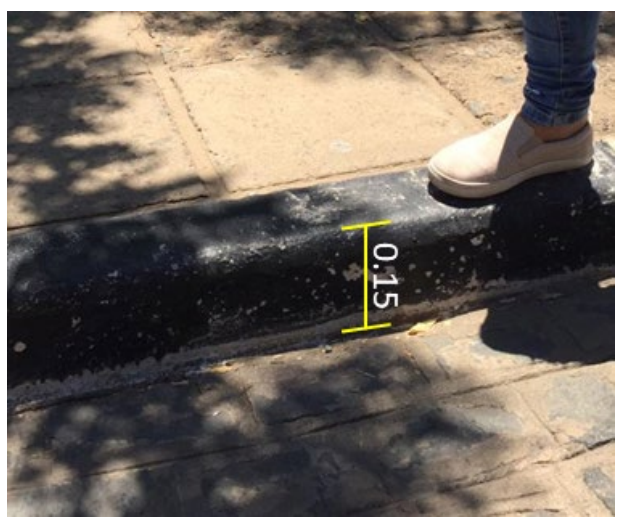

Fonte: Acervo próprio (2019). 


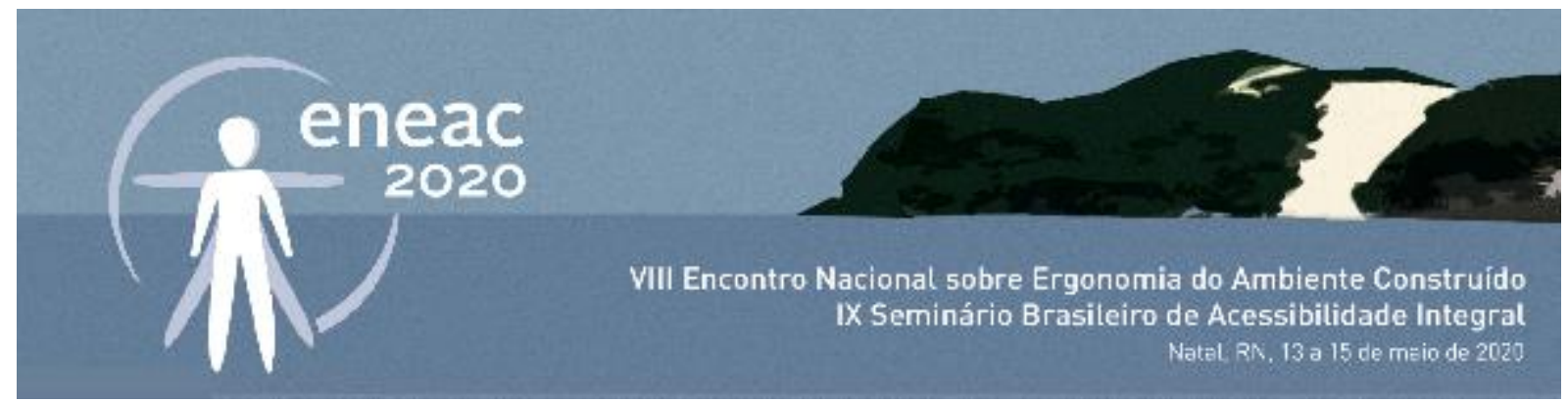

O estacionamento possui 15 vagas, com inclinação a 45 todas de uso comum e nenhuma destinada como vaga acessível. $O$ espaço entre as mesmas é mínimo (Figura 07), e sem possibilidades de inclusão de faixa de transferência. Lembrando também, do difícil acesso partindo da descida do automóvel para a subida na calçada (Figura 08).

Figura 08- Largura da vaga de estacionamento.

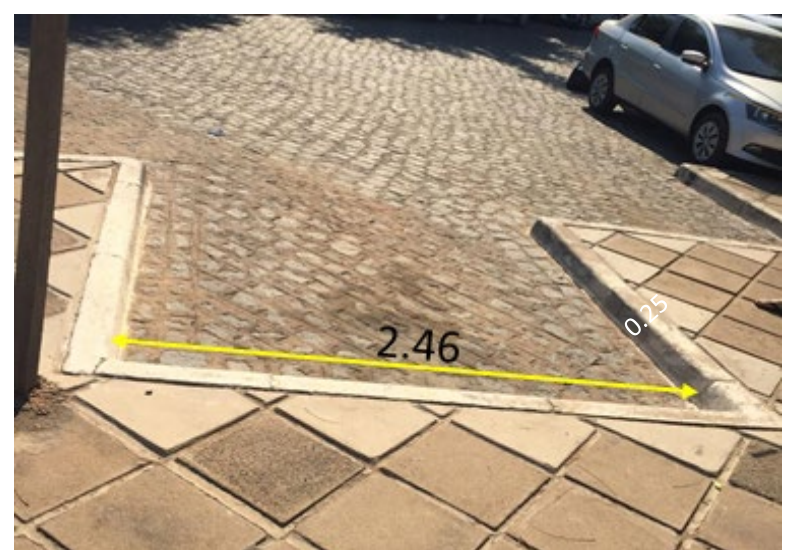

Fonte: Acervo próprio (2019).

Em relação ao interior do terminal é possível perceber que o mesmo não dispõe de um atendimento acessível, visto que os balcões possuem altura irregular e não permitem que o usuário com mobilidade reduzida avance sob o balcão (figura 9), diante a NBR 9050/15, a altura dos balcões deve ser entre $0,75 \mathrm{~m}$ e $0,85 \mathrm{~m}$, com profundidade de $0,30 \mathrm{~m}$ no mínimo.

Figura 9- Balcão de atendimento com medidas irregulares.

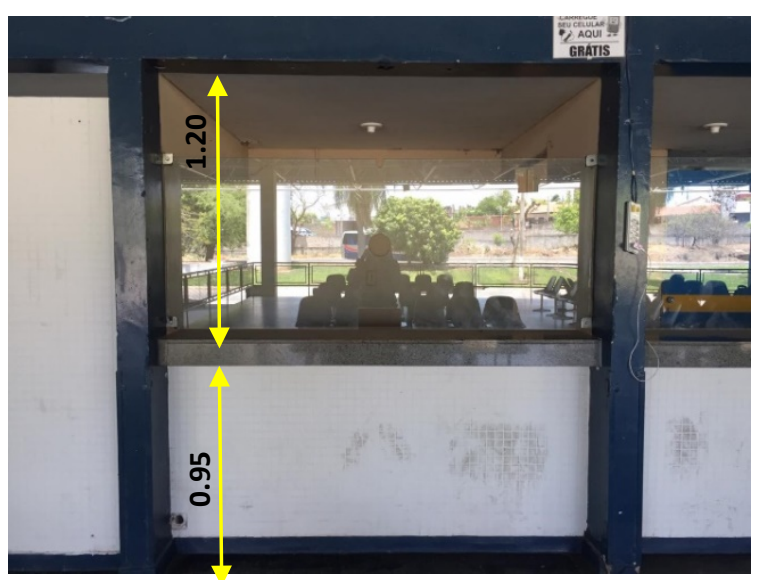

Fonte: Acervo próprio (2019). 


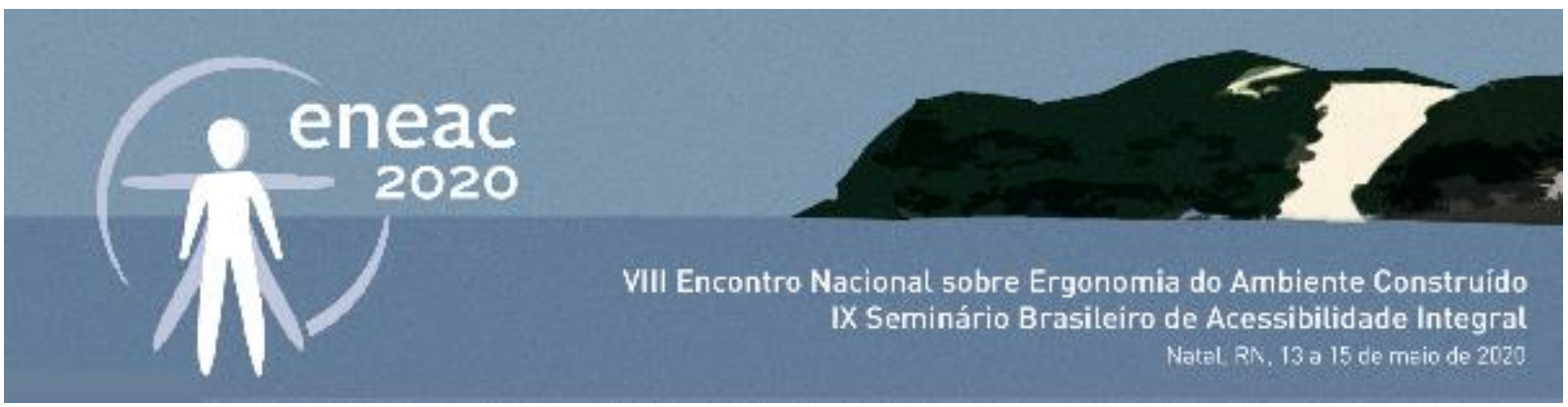

Por se tratar de uma edificação de uso público e que possui grande fluxo de pessoas diariamente, é substancial a presença de banheiros que comportem todas as necessidades dos usuários. O Terminal, neste ano de 2019, está passando por algumas mudanças nos sanitários, depois de 29 anos após sua fundação. Com base nas visitas in loco, evidenciou-se que os mesmos possuem alguns quesitos desfavoráveis e favoráveis conforme a normatização:

- Desfavoráveis

Tendo como base a NBR 9050/15, os banheiros acessíveis, devem estar localizados fora do banheiro de uso comum, com entrada independente, para possibilitar que a pessoa com deficiência possa ter acesso a instalação sanitária na companhia de outra pessoa do mesmo sexo. Com isso, foi observado que os banheiros do terminal, que se encontram em reforma, terão os banheiros acessíveis dentro do banheiro de uso comum (figura 10).

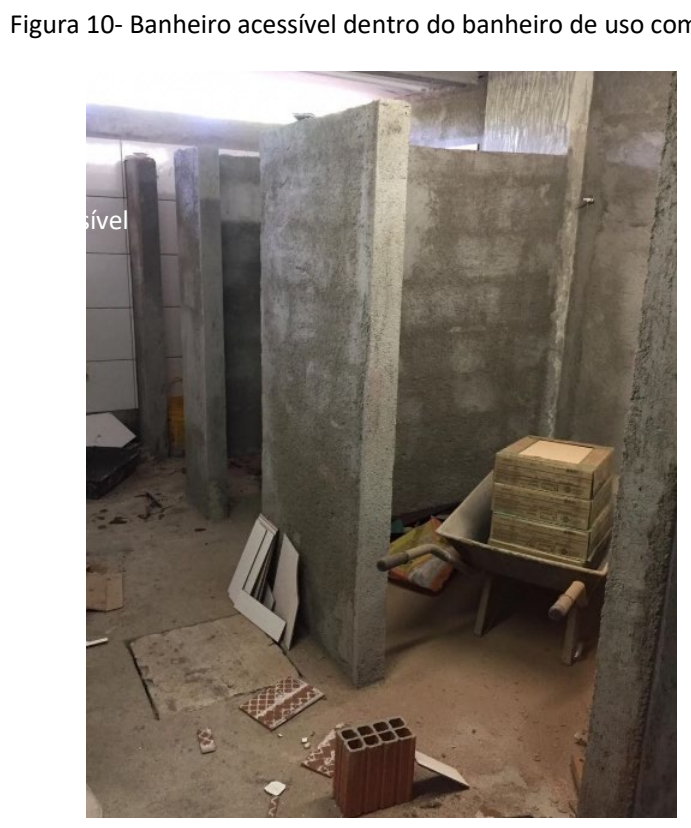

Fonte: Acervo próprio (2019).

Outro ponto desfavorável, encontrado no sanitário masculino, foi a área de aproximação frontal nos mictórios para pessoa com cadeira de rodas, pois, diante da normativa estudada para realização deste trabalho, área deve ter, no mínimo, 0,80m e conter barras de apoio. Contudo, foi constatado que os mictórios têm área frontal inferior ao que consta na normativa (Figura 11). Em conversa com o mestre de obra, o mesmo afirmou que os mictórios não possuirão barras de apoio. 


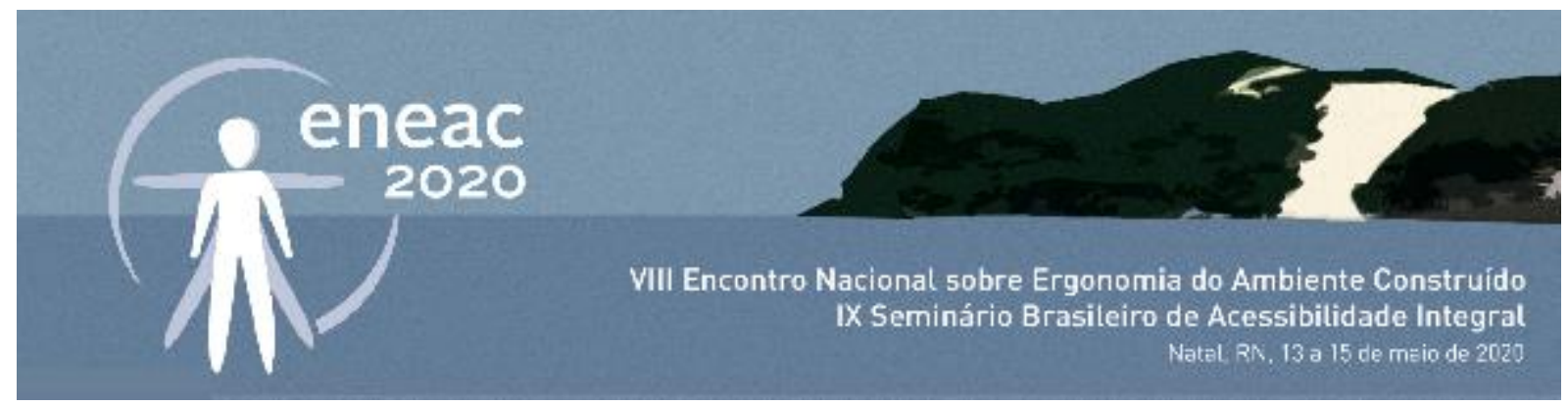

Figura 11- Banheiro masculino com espaçamento irregular.

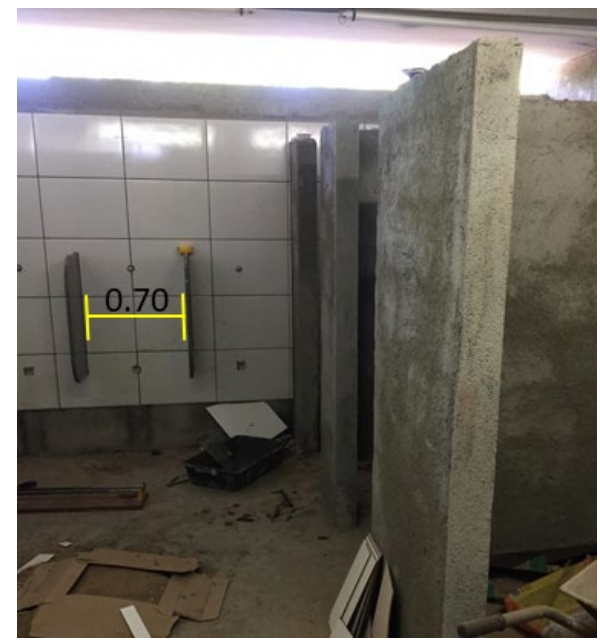

Fonte: Acervo próprio (2019).

- Favoráveis

Para que a pessoa com deficiência realize uso do banheiro acessível, este deve ter as seguintes medidas: 1,70m de largura e 1,50m de comprimento, segundo a NBR 9050/15, assim, pessoa com deficiência pode realizar a manobra com facilidade para utilizar a bacia sanitária e o lavatório. Conforme as medidas retiradas do banheiro acessível, será possível a área de transferência e a realização da manobra da bacia sanitária.

Os mictórios devem ter uma área de aproximação frontal com diâmetro de 0,60m para pessoas com mobilidade reduzida, de acordo com a norma apresentada. Com isso, foi perceptível, que os mictórios estão de acordo com a norma. Para que torne um banheiro acessível, o mesmo deve possuir porta com vão livre de no mínimo $0,80 \mathrm{~m}$, de maneira que permita sua abertura completa, o que foi comprovado nos sanitários do Terminal analisado.

O Terminal possui duas rampas, sendo essas implantadas no portão de embarque e desembarque. Constata-se a falta do cumprimento da norma NBR 9050/15, tendo em vista que as mesmas possuem inclinação acima de $11 \%$. Observa-se ausência de corrimãos e também das sinalizações em Braille, informando sobre elementos que requerem mais atenção (Figura 12). 


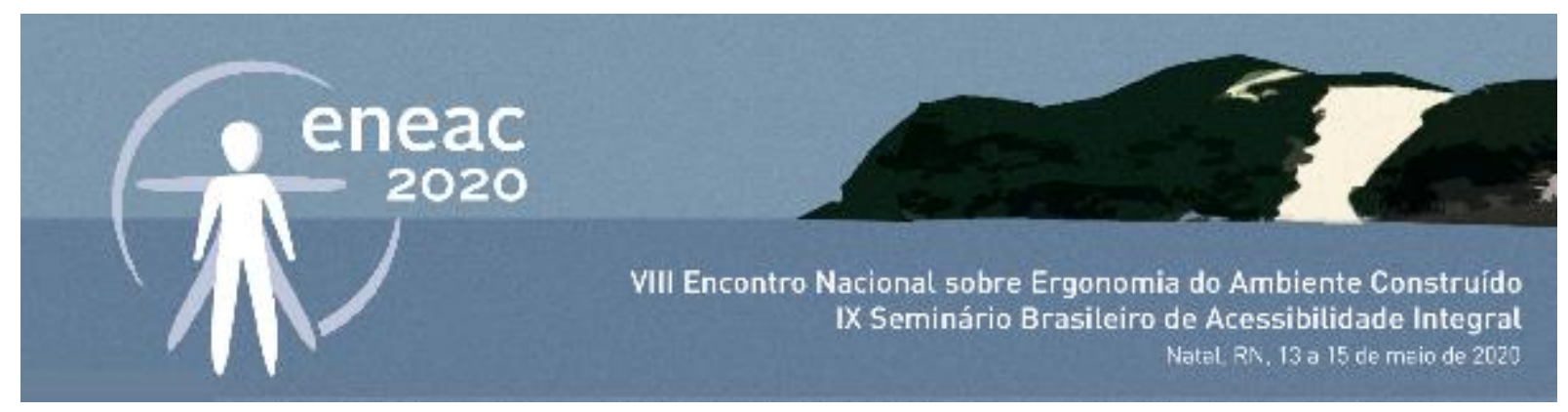

Figura 12- Rampa com inclinação acima de 11\% e a ausência de corrimão.

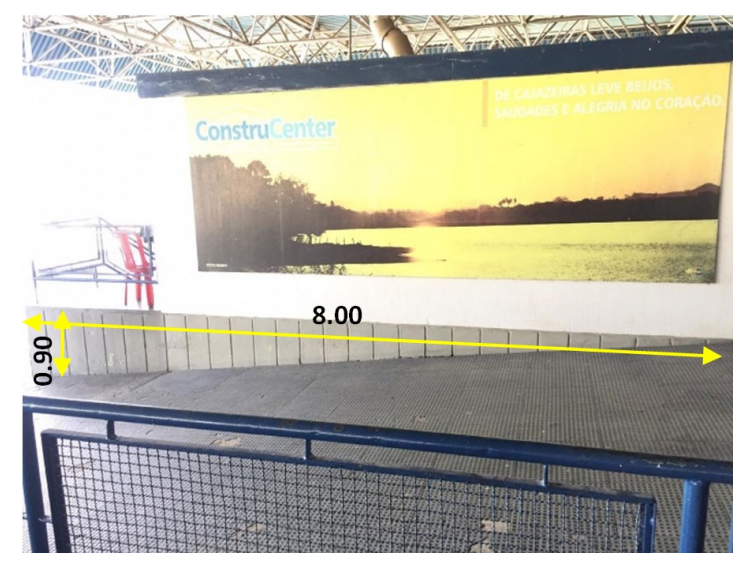

Fonte: Acervo próprio (2019).

O piso das rampas é revestido com material antiderrapante, o mesmo dispõe irregularidades e ausência de piso tátil de alerta no início e término das rampas (Figura 13), o que dificulta a mobilidade dos portadores de deficiência visual. Vale ressaltar, que existem pisos táteis para alerta e para indicar direção.

Figura 13- Rampa com piso irregular e sem piso tátil no início e fim.

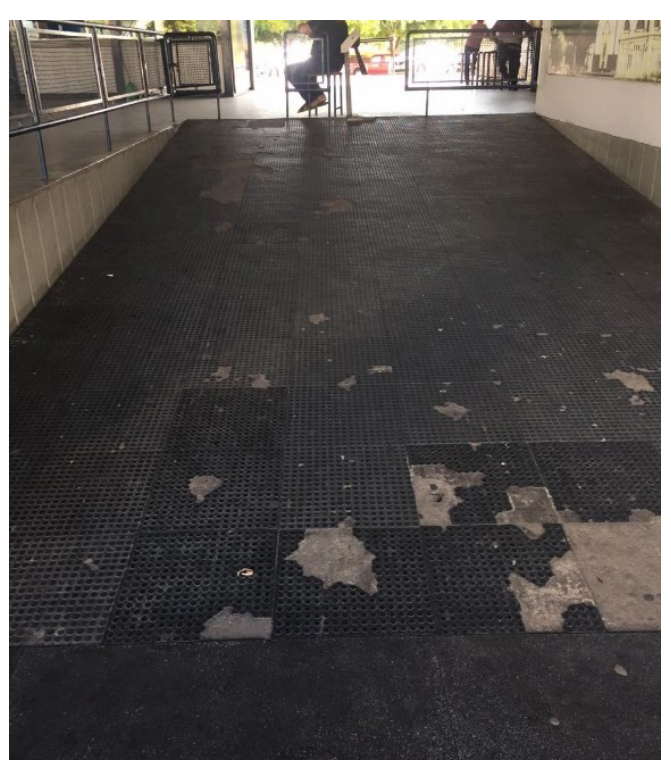

Fonte: Acervo próprio (2019). 


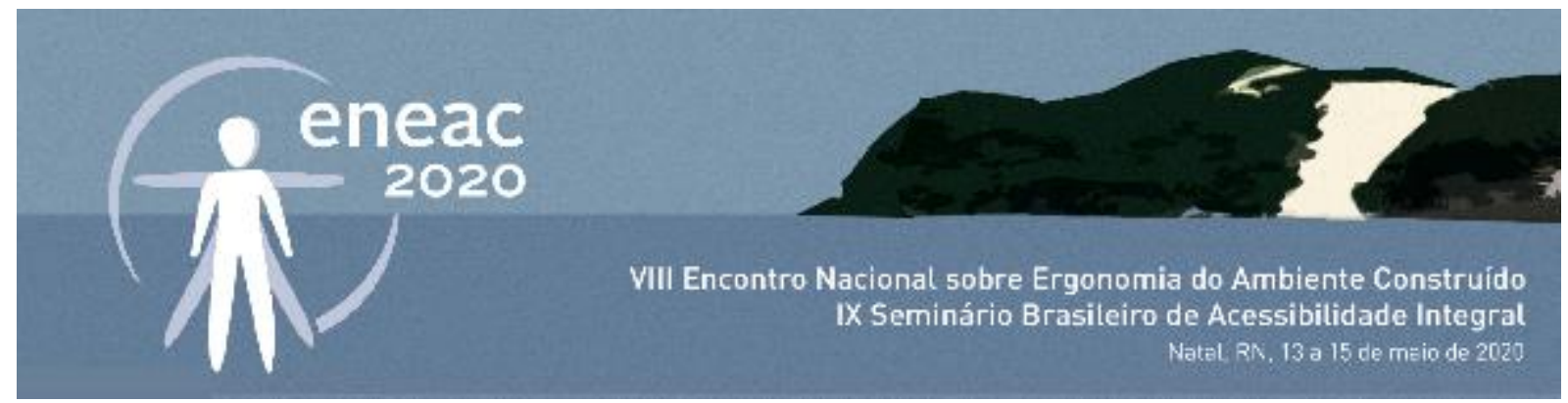

O piso das áreas de circulações internas e externas, é composto por placas de concreto separadas por rejuntes de PVC, em sua maioria está em bom estado, mas possui trechos irregulares de acordo com a Figura 14.

Figura 14- Piso com irregularidades.

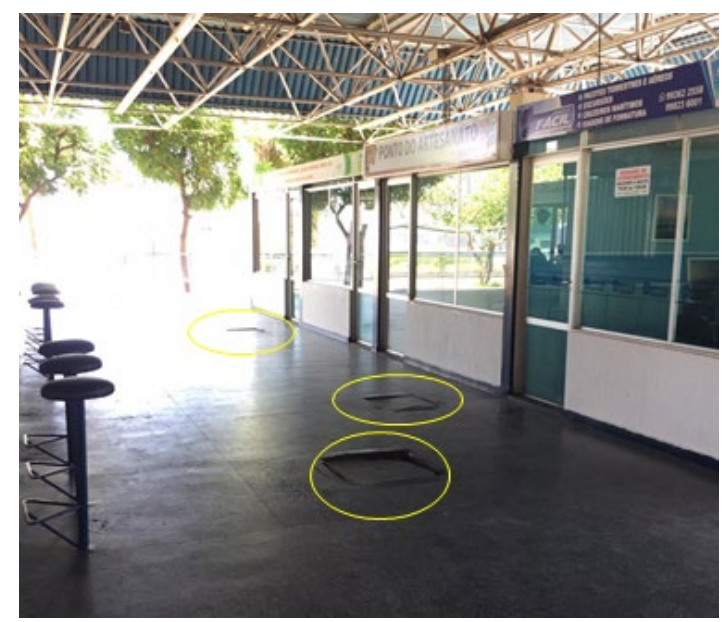

Fonte: Acervo próprio (2019).

Sempre que houver assentos fixos em pontos de embarque e desembarque de transporte público, deve ser garantido um espaço destinado ao portador de cadeira de rodas e pessoas obesas, conforme a NBR 9050/15.

Foi averiguado que os assentos fixos do Terminal não dispõem de um espaço para esses usuários, que deveria ser de $5 \%$ da quantidade total, com mínimo de 1 assento. como também não existe um assento de uso preferencial (gestante/lactante) (Figura 15), sinalizado com o símbolo internacional de acesso, como abordado no fim do tópico 2.0.

Figura 15- Assentos fixos sem espaço para portador de cadeira de rodas e largura inadequada para obeso.

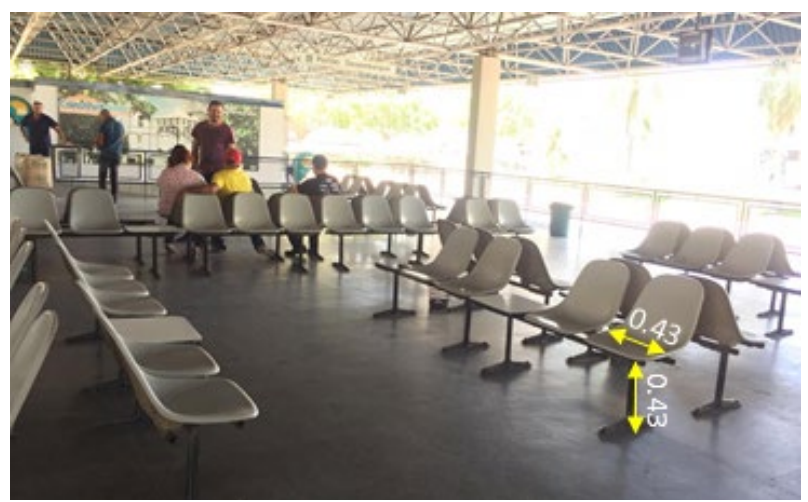

Fonte: Acervo próprio (2019). 


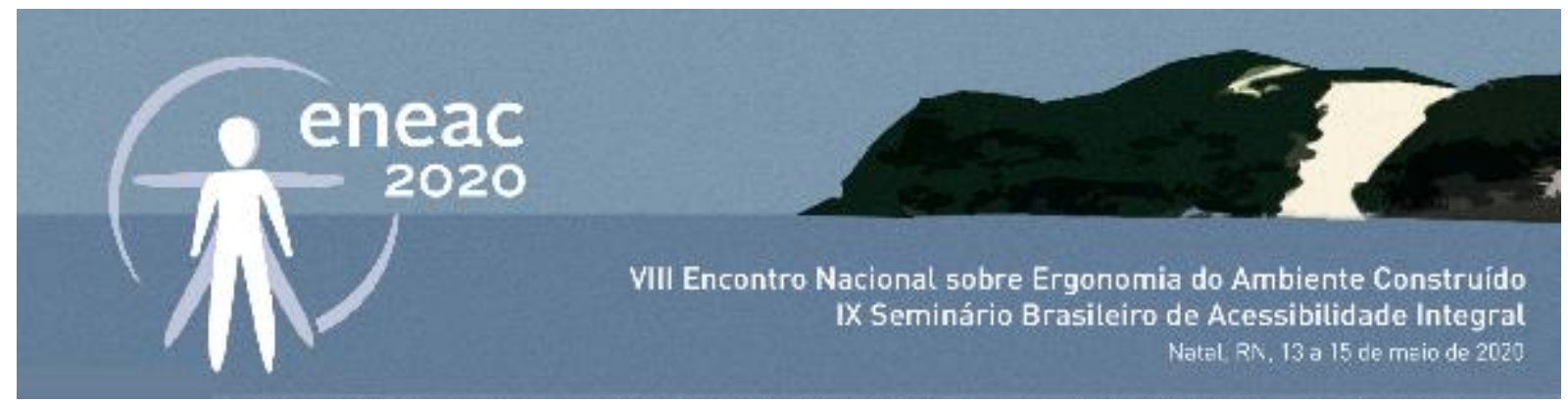

O Terminal desfruta de duas lanchonetes em seu interior, onde as mesmas possuem balcões desapropriados (Figura 16), em conformidade com a NBR 9050/15, na qual diz que os balcões de atendimento devem garantir altura entre $0,75 \mathrm{~m}$ e $0,85 \mathrm{~m}$.

Figura 16- Balcões e assentos desapropriados.

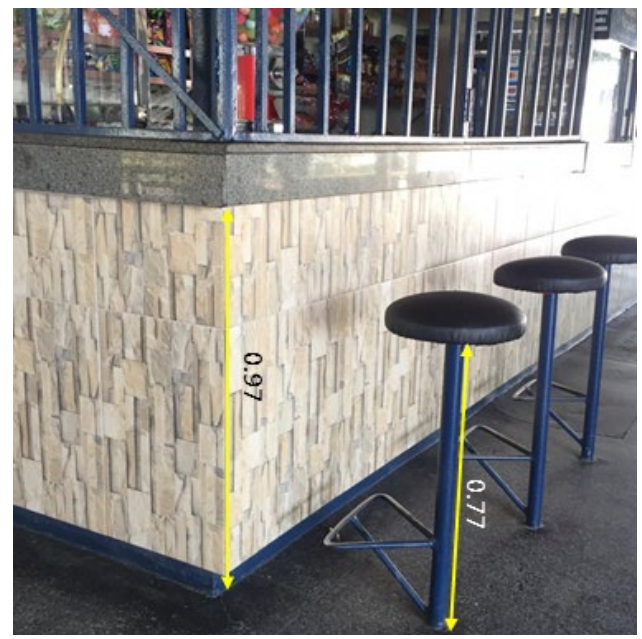

Fonte: Acervo próprio (2019).

Como o Terminal possui grande movimentação de pessoas diariamente, alguns comércios encontram-se instalados no local. Com o pouco acesso conseguido, foi possível perceber a inacessibilidade contida no espaço, a exemplo de portas estreitas e nenhuma informação adicional

Pode-se analisar também, que com essa mínima largura, as possibilidades acessíveis são mínimas. Causando dificuldades não só para deficientes, mas para obesos e usuários com algum tipo de mobilidade reduzida, também.

\section{CONSIDERAÇÕES FINAIS}

Após a análise realizada no Terminal Rodoviário da cidade de Cajazeiras/PB, segundo a NBR 9050/2015, constatou-se como necessária e urgente uma reforma no terminal e seu entorno de forma a garantir a acessibidade física e espacial, além da divulgação e conscientização da importância de espaços públicos mais inclusivos para todos, pois além de ser direito perante lei torna os ambientes mais humanizados.

A partir do diagnóstico encontrado, percebe-se que algumas barreiras físicas são de fácil resolução sem grandes mudanças no terminal, como criar rotas inerligadas desde o estacionamento até 0 embarque, ou mesmo a inserção de pisos táteis para melhor orientação e sinalização tátil e visual.

Apesar de esse trabalho ter diagnosticado barreiras principalmente físicas no terminal, é necessário que para a efetivação de uma reforma construtiva de forma a atender as necessidades reais dos usuários, seja realizada mais pesquisas que somem a esta. Recomenda-se assim, trabalhos voltados a pesquisa de opinião dos transeuntes para captar a percepção e opnião deles, assim como diagnósticos mais aprofundados sobre sinalização e orientação espacial. 


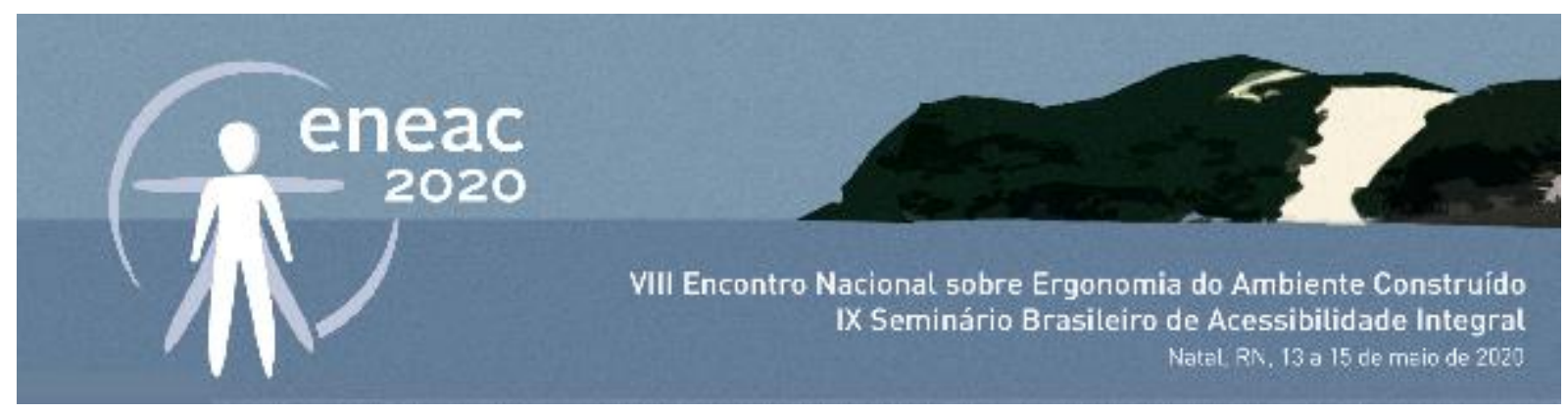

\section{AGRADECIMENTOS}

Gostaríamos de agradecer primordialmente à Deus, que é soberano sobre todas as coisas que nos proporcionou a conclusão desse artigo, com sabedoria e paciência. Em seguida gostaríamos de agradecer à nossa tão carinhosa professora/orientadora, Marjorie Abreu, que nos incentivou, nos apoiou e acreditou na nossa capacidade. Nosso agradecimento também vai para os funcionários do Terminal Rodoviário que foram atenciosos para realização desse trabalho. Enfim, agradecer ao trabalho em dupla, que foi realizado com parceria e aos colegas de sala, que sempre estiveram ao nosso lado.

\section{REFERÊNCIAS}

ASSOCIAÇÃO BRASILEIRA DE NORMAS TÉCNICAS. NBR 9050 - Acessibilidade e edificações, mobiliário, espaços e equipamentos urbanos. Rio de Janeiro, 2015

COSTA FERNANDES, Gabriela. Junta Comercial do Estado da Paraíba. Mais de $\mathbf{1 0}$ mil passageiros circula mensalmente na rodoviária de Cajazeiras. 2019. Disponível em: <http://jucep.pb.gov.br/der/noticias/mais-de-10-mil-passageiros-circulam-mensalmente-na-rodoviariade-cajazeiras>. Acesso em: 18 set. 2019.

IBGE, Censo: Amostra - Pessoas com deficiência. 2010. Disponível em:

<https://cidades.ibge.gov.br/brasil/pb/cajazeiras/pesquisa/23/23612>. Acesso em: 20 set. 2019.

KINSKY, Marcos (2004). "Serpro garante acessibilidade digital para portadores de necessidades especiais". Disponível em: <http://www.serpro.gov.br/noticiasSERPRO/0040618_07/view>. Acesso em: 31 out. 2019.

LAMÔNICA, Dionísia Aparecida Cusin et al. Acessibilidade em ambiente universitário: identificação de barreiras arquitetônicas no campus da USP de Bauru. Rev. bras. educ. espec. 2008, vol.14, n.2, pp.177-188. 2008.

DISCHINGER, M., BINS ELY, V. H. M., PIARDI, S. M. D. G. Promovendo acessibilidade espacial nos edifícios públicos: Programa de Acessibilidade às Pessoas com Deficiência ou Mobilidade Reduzida nas Edificações de Uso Público. Florianópolis: MPSC, 2012. 161 p.: il., tabs., mapas.

SASSAKI, Romeu Kazumi (2004). Acessibilidade: uma chave para a inclusão social. Revista Nacional de Reabilitação, São Paulo, p. 10-16, Ano VII, mar./abr. 2004. 